\title{
The Strategy of Constructing Enterprise Human Resource Performance Management System
}

\author{
Zhu Weibin \\ Guangdong Polytechnic College, Guangdong, 526100, China
}

Keywords: enterprise human resources; performance management system; system construction

Abstract: Since the beginning of the new period, with the deepening of the reform of China's market economic system, the market competition pressure faced by enterprises has also increased. How to promote the survival and development of enterprises in such a situation has become a multitude of the primary problem facing the industry. Among the many methods, the enterprise human resource performance management system plays a huge role in promoting the survival and development of the enterprise under the premise of fully stimulating the enthusiasm, initiative and creativity of the employees. The paper combines years of enterprise human resource management work practice, firstly summarizes the enterprise human resources performance management system and its important role, and then puts forward the views on the system construction for the reference of the majority of peers.

\section{Introduction}

Reasonable construction of the enterprise's human resources performance management system is important for the long-term development of the enterprise, as well as for the current stable survival and competitiveness. In strengthening the human resources management of enterprises, it is necessary to comprehensively consider all aspects of talents' assessment, training and selection, in order to reasonably construct an effective human resource performance management system. When constructing a human resource performance management system, enterprises need to consider whether the system is effective, feasible, reasonable and scientific, because it is not only related to the quality and level of human resource management and structure, but also to the enterprise ${ }^{[1]}$.

2. Overview of enterprise human resources performance management system and its important role

\subsection{Enterprise Human Resource Performance Management System Meaning}

Through the research of relevant literature and the practice of the author, the enterprise human resources performance management system mainly refers to the management system that integrates the daily work information of employees and the performance evaluation. The "wheel" model shown in Figure 1 below can be effectively reflecting the development process of the company: 


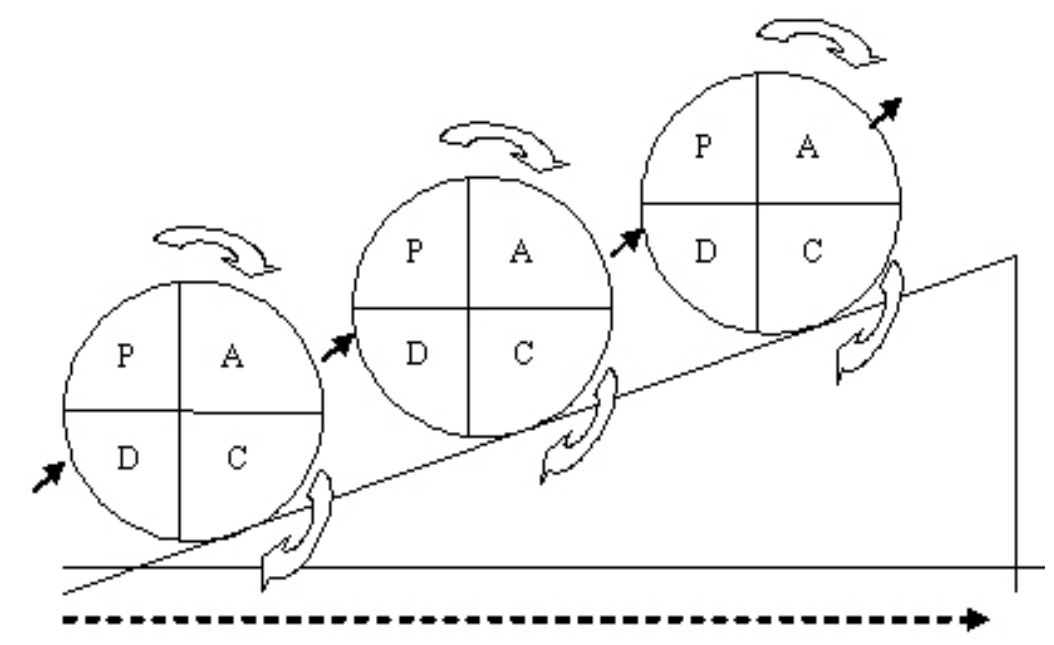

Figure 1 The "wheel” model of enterprise performance management in the loop

As shown in the "wheel” model shown in Figure 1 above, in the development of the enterprise, excellent employees are constantly developing, and employees with poor performance are gradually losing. This will not only enable the company to evaluate the employee's work efficiency, but more importantly, the company can use the corresponding reward and punishment standards in the performance appraisal to ensure that its tasks are completed on time and in a timely manner ${ }^{[2]}$. .

\subsection{The important role of enterprise human resources performance management system}

According to the author's research on the enterprise human resources performance management system, the system has the following two important functions: First, it helps to enhance the competitiveness of enterprises. After implementing the human resources performance management system, the enterprise can first decompose its development goals by means of the performance management indicators in the system, and then allocate the corresponding tasks according to the responsibilities of different departments on the basis of this, and finally the departments according to the departmental performance The management indicators and the assigned tasks are assigned to each employee reasonably in combination with the actual number of employees in the department. As shown in Figure 2 below, the enterprise human resource performance management can effectively coordinate the efforts of all people.

$\nearrow:$ The direction of personal or team effort

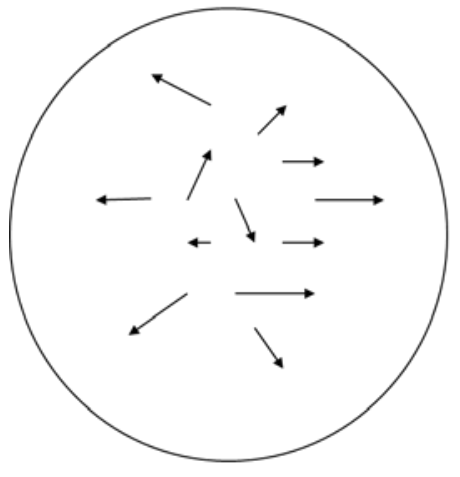

Before implementation

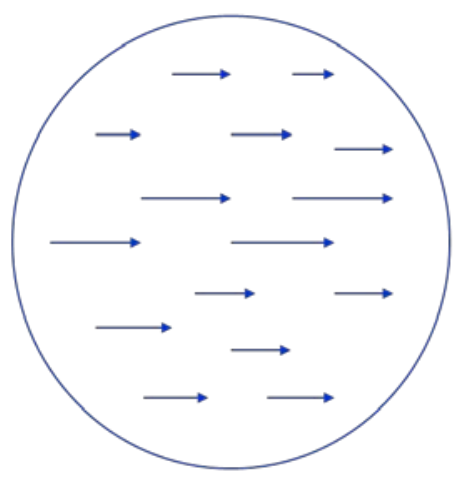

After implementation

Figure 2 The role of enterprise human resources performance management: the direction of coordinating the efforts of business owners 
As shown in Figure 2 above, the way to assign enterprise development tasks step by step enables them to enhance their competitiveness while efficiently completing the corresponding work. Secondly, it helps to stimulate the enthusiasm, initiative and creativity of employees. After implementing the human resources performance management system, the enterprise shall formulate a corresponding work assessment reward and punishment mechanism by fully combining the work contents of different departments and the department performance management indicators, that is, the enterprise will give certain salary rewards according to the mechanism when the employees exceed the prescribed work tasks ${ }^{[3]}$.

\section{Construction of enterprise human resources performance management system}

\subsection{Performance appraisal plan formulation}

In a perfect enterprise human resource performance management system, the performance appraisal plan can be said to be an extremely important and fundamental link, and with the help of this plan, not only can the employees clearly understand the purpose of performance appraisal, but more importantly, Let them fully play a huge role in ensuring the enterprise human resources performance management system based on the familiarity with the performance appraisal such as methods, standards and weights.

\subsection{Establishment of performance appraisal method library}

Through research, it is found that the assessment methods used in the enterprise human resource performance management system are various. Different methods differ in the assessment criteria and use conditions, which leads to the same object assessment. The results are different depending on the method used. Therefore, in order to ensure the accuracy of the enterprise human resources performance management system assessment, enterprises should establish a rich library of performance appraisal methods, so that enterprises can take appropriate measures by means of this. In combination with the author's practice, the more methods currently used in the performance management system assessment are: balanced scorecards, key events, and $360^{\circ}$ assessments. Therefore, the author believes that these three should be included in the enterprise performance appraisal method library.

- First, the balanced scorecard method. In the human resource performance management system, the enterprise develops the employee work balance scorecard model according to the relevant performance appraisal method, and then integrates the balance of the employees such as education and training, post promotion, and salary and benefits with their vital interests. Card management;

- Second, the $360^{\circ}$ assessment method. The evaluation method of the human resources performance management system is special. It mainly conducts questionnaire surveys on all the people around the assessment object, such as leaders, colleagues, subordinates and customers. It generally involves all aspects of the performance, work attitude and overall quality of the assessment objects. Content;

- Third, the key event law. Different from the above two assessment methods, the key event method is mainly to assess the key contribution of employees to the overall development of the enterprise or the degree of damage to the enterprise. If the contribution value (value of interest) reaches the set value of the assessment method the standard should be rewarded ${ }^{[4]}$.

In combination with practice, the core of the key event method lies in the set assessment criteria, for which the enterprise must be set strictly in accordance with relevant regulations. 


\section{Rationally construct the enterprise human resources performance management system}

\subsection{Key Performance Indicators Act}

The key performance indicator method is a form of management indicators that can quantify performance, and can be used to set key parameter information of specific input and output terminals within the enterprise management. Usually, the business unit will adopt this performance appraisal evaluation method performance appraisal, but it is not applicable to the production service staff.

\subsection{Mutual balance indicator system}

This is an analysis of internal process indicators, customer indicators and financial indicators, and then periodic performance evaluation. In addition, we must establish a modern human resources performance assessment concept. If the company wants to improve the enthusiasm of employees, it is necessary to link the salary of employees to the structure of performance appraisal. As shown in Figure 3 below, it is some important indicators of enterprise human resources performance management:

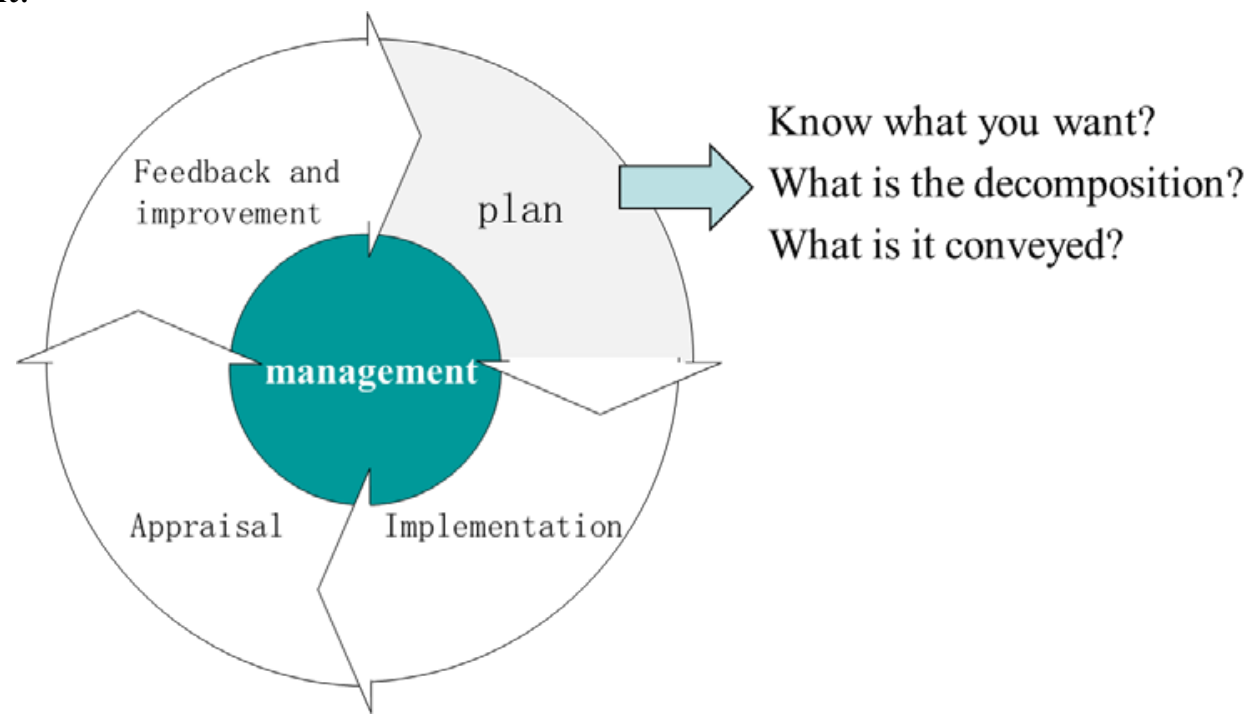

Figure 3 Indicators for enterprise human resource performance management

As shown in Figure 3 above: When formulating performance appraisal, the managers of enterprises must have the concept of human resources performance appraisal of modern enterprises, communicate actively and effectively with employees, and help employees solve some practical difficulties in time. This will not only effectively improve the enthusiasm of employees, but also improve the performance of employees, and further promote the healthy development of the company ${ }^{[5]}$.

\section{Conclusions}

Under the current wave of market economy, the competition of modern enterprises is becoming increasingly fierce. Whether to effectively construct a sound and reasonable enterprise human resources performance management system is related to the survival and development of enterprises. At the same time, we must ensure the effectiveness; feasibility and scientificity of the system to improve the quality and level of human resource management, further enhance the comprehensive 
competitiveness of enterprises, and ultimately promote the healthy and sustainable development of enterprises.

\section{References}

[1] Gu Y, Lian Q, Jian W. Breaking the monolith: Strategy, variety, and performance of enterprise information systems [J]. Journal of Systems Science \& Systems Engineering, 2017(2):1-44.

[2] Tweedie D, Wild D, Rhodes C, et al. How Does Performance Management Affect Workers? Beyond Human Resource Management and Its Critique [J]. International Journal of Management Reviews, 2018.

[3] Page S J, Bentley T, Teo S, et al. The dark side of high performance human resource practices in the visitor economy [J]. International Journal of Hospitality Management, 2018, 74:122-129.

[4] Gile P P, Buljac-Samardzic M, Klundert J V D. The effect of human resource management on performance in hospitals in Sub-Saharan Africa: a systematic literature review [J]. Human Resources for Health, 2018, $16(1): 34$.

[5] Petersson N P. Managing a "People Business" in Times of Uncertainty: Human Resources Strategy at Ocean Transport \& Trading in the 1970s [J]. Enterprise \& Society, 2018, 19(1):1-36. 